\title{
Periodontal clinical features of bronchial asthma patient using inhalation drugs
}

\author{
Maria Efrinta Ginting ${ }^{1}$, Rosiliwati Wihardja ${ }^{2}$, Dyah Nindita Carolina ${ }^{1 *}$ \\ ${ }^{1 *}$ Department of Periodontics, Faculty of Dentistry Universitas Padjadjaran, Indonesia \\ 2Department of Oral Biology, Faculty of Dentistry Universitas Padjadjaran, Indonesia
}

\begin{abstract}
Introduction: Bronchial asthma patients use inhalation drugs as therapy to achieve a controlled asthma state. Inhaled corticosteroids and $\mathrm{B}_{2}$ agonists are the medication that is being used in this case. Prolonged use of inhalation drugs will affect the health of periodontal tissue. The effect of these drugs can reduce the periodontal defense mechanism and increase the risk of periodontal disease. This study aims to determine the periodontal clinical features of bronchial asthma patients using inhalation drugs. Method: This research was a descriptive study. The sample of the study were 22 females and 8 males bronchial asthma patients at the Community Lung Health Center of Bandung (Balai Besar Kesehatan Paru Masyarakat Bandung/BBKPM Bandung) who had been using inhalation drugs for at least one year. The periodontal clinical feature was assessed by employing a Community Periodontal Index (CPI) modified with probing the gingival sulcus to assess the presence of gingival bleeding, periodontal pocket, and loss of clinical attachment where then a periodontal status was obtained. The periodontal status data were then processed using the periodontitis case definitions from the Centers for Disease Control and Prevention/ American Academy of Periodontology (CDC/AAP) to determine periodontal disease in asthmatics patients. Results: Clinical features of gingival bleeding were found in 26 asthmatic patients (86.7\%), periodontal pockets in 18 asthmatic patients (60\%), and loss of clinical attachment in 27 asthmatic patients (90\%). Based on the CDC/AAP case definition, 23 asthmatic patients (76.7\%) had periodontitis. Bronchial asthma patients who used inhalation drugs had a risk of periodontitis.Conclusion: Bronchial asthma patients who used inhalation drugs for at least one year Had gingival bleeding and loss of clinical attachment and periodontal pocket.
\end{abstract}

Keywords: Bronchial asthma; Inhalation drugs; CPI modified Index; CDC/AAP

p-ISSN: 1979-0201; e-ISSN: 2549-6212; Available from: http://jurnal.unpad.ac.id/pjd/article/view/29739

DOI: 10.24198/pjd.vol33no2.29739

Submission: Okt 06, 2020; Accepted: Nov 29, 2021; Published online: Nov 30, 2021

\section{INTRODUCTION}

Bronchial asthma is a chronic respiratory disease that affects $1-18 \%$ of the population of various countries. ${ }^{1}$ The number of asthma patients in the world reaches 300 millions and is estimated to increase by 100 million in 2025. 2,3,4 Deaths caused by asthma occur in countries with low to moderate economic levels, including Indonesia. ${ }^{5}$ The prevalence of bronchial asthma in Indonesia, based on the results of Indonesia Basic Health Research (Riskesdas) 2018, reached 2.4\% of the

Corresponding author: Dyah Nindita Carolina, Department of Periodontics, Faculty of Dentistry Universitas Padjadjaran, Indonesia. Jalan Sekeloa Selatan I, West Java, Indonesia, 40132. Phone: +62 815-6132-636; Email: dyah.nindita@unpad. $\underline{\text { ac.id }}$ 
total population of Indonesia, which is around 6,456 millions people. West Java, where the Community Lung Health Center of Bandung located, is a province with an asthma prevalence that exceeds the national rate and ranks 10 th out of 33 provinces in Indonesia. ${ }^{6}$

Bronchial asthma is defined as a disease with chronic inflammation of the airways that involves many inflammatory cells and results in bronchial hyper responsiveness towards various stimuli and signed by airway obstruction that is reversible with or without treatment. ${ }^{7,8,9}$ Asthma is characterized by episodic or persistent symptom of wheezing, dyspnea, and cough. ${ }^{10,11}$ Asthma treatment uses bronchodilator/reliever drugs to dilate the airways, and anti-inflammatory/ controller drugs to treat inflammation and control asthma. Both bronchodilator and controller drugs can be administered by inhalation, oral, and parenteral (subcutaneous, intramuscular, intravenous). The administration of the drug by inhalation is considered more efficient because it works faster on the target organ and has minimal systemic effects. Short-acting B2 agonists are the type of bronchodilator drugs that are most commonly used, and inhaled corticosteroids, which are combined with long-acting B2 agonists, are in the type of controller drugs that are widely used because of their effectiveness in controlling asthma. ${ }^{1}$

The long-term use of $B_{2}$-agonists and inhaled corticosteroids affect the periodontal tissue. The content of inhalation drugs can reduce the secretion of saliva which is exacerbated by the activation of inflammatory mediators in the gingiva. Prolonged use of inhalation drugs results in a decrease of the defense mechanism of the periodontal tissue which causes periodontal tissue destruction, and worsen by the patient's inadequate oral hygiene. ${ }^{12}$

Periodontal tissue destruction that is not immediately treated can lead to the progression of periodontal disease to a more advanced or severe stage. ${ }^{13}$ The level of knowledge regarding correct oral health care among Indonesian people is still low, as a result, it can indirectly increase the risk of periodontal disease. ${ }^{6}$ Both of these conditions will interfere patient productivity and quality of life.Data regarding the periodontal clinical feature in bronchial asthma patients in
Indonesian society is still low. This study aims to determine the clinical features of periodontal tissue and the percentage of periodontal disease in bronchial asthma patient using inhalation drugs at the Community Lung Health Center of Bandung (Balai Besar Kesehatan Paru Masyarakat Bandung/ BBKPM Bandung).

\section{METHODS}

This descriptive research was conducted at Community Lung Health Center of Bandung (Balai Besar Kesehatan Paru Masyarakat Bandung/ BBKPM Bandung) during February-March 2020. The study was carried out in 30 subjects with inclusion criteria as follows: has been diagnosed with bronchial asthma by BBKPM doctors, use inhalation drugs for at least one year, and over 17 years old; furthermore, the exclusion criteria were patients suffering from systemic disease including diabetes mellitus, COPD (Chronic Obstructive Pulmonary Disease), hypertension, and heart disease, as well as patients who were undergoing antibiotic therapy and antiseptics usage in the last 3 months.

The research variables consisted of dependent variables, that was periodontal tissue of the bronchial asthma patient and independent variables that were $B 2$ agonists and inhaled corticosteroids used as bronchial asthma therapy. The periodontal status assessment was carried out based on the CPI modified index proposed by WHO 2013.

It examined the presence of gingival bleeding and periodontal pockets of all teeth in the oral cavity, and loss of attachment from the index tooth that was the representative of each tooth sextants based on the highest score. The research tools and materials were the WHO CPI probe, mouth mirror, trays for laying sterile tools, water and cups, masks, gloves, disinfectant liquid, tissues, headlamp, examination forms, questionnaires, informed consent, and stationery.

Initially, all participants were interviewed through questionnaires that considered the history of asthma and oral health status. Then, the periodontal status was assessed by probing into the gingival sulcus of all teeth to record the presence of gingival bleeding and periodontal pockets, then probing the index tooth to assess the presence of loss of attachment. The periodontal 
status data were then processed using the CDC/ AAP case definition to determine periodontitis disease in the subjects. The selected participants were informed of how the research would be conducted, and a consent form was signed. This

\section{RESULTS}

Table 1 presents data and subject characteristics based on gender and age. Based on the subject's gender, most subjects are females $(73,3 \%)$, while study was approved by the Health Research Ethics Commission (Ethics committee approval number: 88/UN6.KEP/EC/2020 by the Health Research Ethics Commission of the Faculty of Medicine Universitas Padjadjaran).

males only $26,7 \%$. Based on the age, 17-34 years old is only 2 subjects $(6,7 \%)$, and most subjects are $45-54$ years old (40\%). This result shows that all of the subjects have passed the puberty phase and are dominated by females.

Table 1. Characteristics of subjects based on gender and age

\begin{tabular}{cccc}
\hline & & $\mathrm{N}$ & $(\%)$ \\
\hline \multirow{2}{*}{ Gender } & Man & 8 & 26.7 \\
& Woman & 22 & 73.3 \\
\hline \multirow{3}{*}{ Age } & $17-34$ years old & 2 & 6.7 \\
& $35-44$ years old & 11 & 36.7 \\
& $45-54$ years old & 12 & 40.0 \\
& $55-64$ years old & 3 & 10.0 \\
\hline
\end{tabular}

Table 2. Characteristic of asthma subjects seen from the duration of using inhalation drugs, level of asthma symptom control, type of inhalation drugs, and mouth breathing during asthma attacks

\begin{tabular}{|c|c|c|c|}
\hline & & $\mathrm{N}$ & (\%) \\
\hline \multirow{3}{*}{ Duration of using inhalation drugs } & $1-3$ years & 24 & 80.0 \\
\hline & 4-5 years & 4 & 13.3 \\
\hline & $\geq 6$ years & 2 & 6.7 \\
\hline \multirow{3}{*}{ Level of asthma symptom control } & Well controlled & 4 & 13.3 \\
\hline & Partly controlled & 14 & 47.7 \\
\hline & Uncontrolled & 12 & 40.0 \\
\hline \multirow{3}{*}{ Single inhalation drugs (SABA) or (ICS-LABA) } & Seretide (DPI) & 10 & 33.3 \\
\hline & Symbicort (DPI) & 4 & 13.3 \\
\hline & Berotec $(\mathrm{MDI})$ & 1 & 3.3 \\
\hline \multirow{5}{*}{$\begin{array}{l}\text { Combination inhalation drugs } \\
\text { (SABA), (ICS-LABA) }\end{array}$} & Seretide (DPI), salbulin (MDI) & 5 & 16.7 \\
\hline & Seretide (DPI), berotec (MDI) & 4 & 13.3 \\
\hline & Symbicort (DPI), salbulin (MDI) & 2 & 6.7 \\
\hline & Symbicort (DPI), berotec (MDI) & 2 & 6.7 \\
\hline & Seretide /symbicort (DPI), retaphyl (tablet) & 2 & 6.7 \\
\hline \multirow{2}{*}{ Mouth breathing during asthma attacks } & Yes & 14 & 46.7 \\
\hline & No & 16 & 53.3 \\
\hline
\end{tabular}

Table 2 presents the characteristics of asthma in the research subjects. A total of 24 subjects $(80 \%)$ had used inhalation drugs for 1-3 years. The level of control of asthma symptoms was found in 4 subjects (13.3\%) with well controlled asthma symptoms, 14 subjects (46.7\%) having partly controlled asthma symptoms and a total of 12 subjects (40\%) having uncontrolled asthma symptoms. Inhalation drugs used by subjects were divided into two categories, single inhalation drugs and combinations (using more than one type of drug). From the single inhalation drugs, seretide was the most widely used $(33.3 \%$ of all subjects) and from the combination group, the combination of seretide and salbulin was the most widely used (16.7\% of all subjects). A total of 14 subjects (46.7\%) always breathed through their mouths when an asthma attack occurred.Table 3 presents the characteristics of the oral health status of the subject.

A total of 25 subjects $(83,3 \%)$ brushed their teeth twice or more a day with the use of toothbrush as a single tool in cleansing being the choice most chosen by 27 subjects (90\%). 14 subjects $(46,7 \%)$ had no visit to the dentist during the past one year and 8 subjects $(26,7 \%)$ had never visited a dentist in their lifetime. The habit of consuming sweet foods was quite high in this study where 15 subjects (50\%) consumed sweet foods/drinks several times a day. 
Table 3. Characteristics of the oral health status of subjects seen from the tooth brushing habits, tooth/gum cleansing tools, dentist visit during the past one year, and consumption of sweet

\begin{tabular}{cccc}
\hline & & $\mathbf{N}$ & $\mathbf{( \% )}$ \\
\hline \multirow{2}{*}{ Tooth brushing habits } & Once a day & 5 & 16.7 \\
& & Twice or more a day & 83.3 \\
Tooth/gum cleaning tools & Toothbrush & 27 & 90.0 \\
& Toothbrush plus other tools (dental floss, toothpicks) & 3 & 10.0 \\
& Once & 5 & 16.7 \\
Dentists visit during the & Twice & 2 & 6.7 \\
past one year & $>4$ times & 1 & 3.3 \\
& Had no visit to dentist during the past one year & 14 & 46.7 \\
Consumption of sweet & Never received a dental care/visited a dentist & 8 & 26.7 \\
foods/drinks & Several times a week & 7 & 23.3 \\
& Everyday & 8 & 26.7
\end{tabular}

Table 4. Periodontal clinical features of subjects assessed from three indicators, gingival bleeding, periodontal pocket, and loss of attachment

\begin{tabular}{cccc}
\hline & & $\mathrm{N}$ & (\%) \\
\hline \multirow{2}{*}{ Gingival bleeding } & Absence & 4 & 13.3 \\
& Presence & 26 & 86.7 \\
Periodontal Pocket & Absence & 12 & 40.0 \\
& Presence & 18 & 60.0 \\
Type of pocket $(\mathrm{n}=18)$ & Shallow pocket $(4-5 \mathrm{~mm})$ & 18 & 100.0 \\
& Deep pocket $(\geq 6 \mathrm{~mm})$ & 0 & 0.0 \\
& $0-3 \mathrm{~mm}$ & 3 & 10.0 \\
Loss of attachment & $4-5 \mathrm{~mm}$ & 18 & 60.0 \\
& $6-8 \mathrm{~mm}$ & 9 & 30.0 \\
& $9-11 \mathrm{~mm}$ & 0 & 0.0 \\
\hline
\end{tabular}

Table 4 summarizes the periodontal clinical features of all subjects using 3 indicators referred to the modified CPI index. The first indicator is gingival bleeding which is assessed from all the teeth in the subject that can be examined. A total of 26 subjects $(86.7 \%)$ in this study have gingival bleeding which indicated the presence of inflammation in the periodontal tissue. ${ }^{14}$

The second indicator is periodontal pocket examination. Periodontal pocket is a pathological deepening of the gingival sulcus and indicates a further inflammation of the gingiva. ${ }^{15}$ In this study, 18 subjects $(60 \%)$ have shallow pockets with a depth of $4-5 \mathrm{~mm}$. The Latest indicator is the loss of attachment assessed from the index teeth representative of the 6 sextants. Clinical attachment loss is the lifetime accumulation history of periodontal disease in each individual. The measurement of clinical attachment loss is used as a parameter in periodontitis diagnosis. ${ }^{16}$ In this study, more than half of the subject population or a total of 18 subjects $(60 \%)$ have clinical attachment loss of $4-5 \mathrm{~mm}$.

This may be caused by the medication being used by the subject and also the changes in immune function in the asthma disease itself. The increasing levels of IgE in bronchial asthma patient gingival tissue which may result in hypersensitivity reaction and decrease in IgA levels may lead to periodontal destruction. ${ }^{17}$

Table 5. Periodontal disease in subjects

\begin{tabular}{ccc}
\hline Periodontal diagnosis & $\mathbf{n}$ & (\%) \\
\hline No periodontitis & 7 & 23.3 \\
Periodontitis & 23 & 7.7 \\
\hline Mild Periodontitis & 1 & 4.3 \\
Moderate Periodontitis & 22 & 95.7 \\
Severe Periodontitis & 0 & 0.0 \\
\hline
\end{tabular}

Table 5 presents the total of Periodontal disease in subjects determined by periodontal pockets and loss of attachment according to the Centers for Disease Control and Prevention (CDC) and 
the American Academy of Periodontology (AAP). The total of periodontitis cases was $76.7 \%$ or 23 subjects, with $4.3 \%$ of them having mild periodontitis and $95.7 \%$ of them having moderate periodontitis, the results of this test periodontitis there are differences
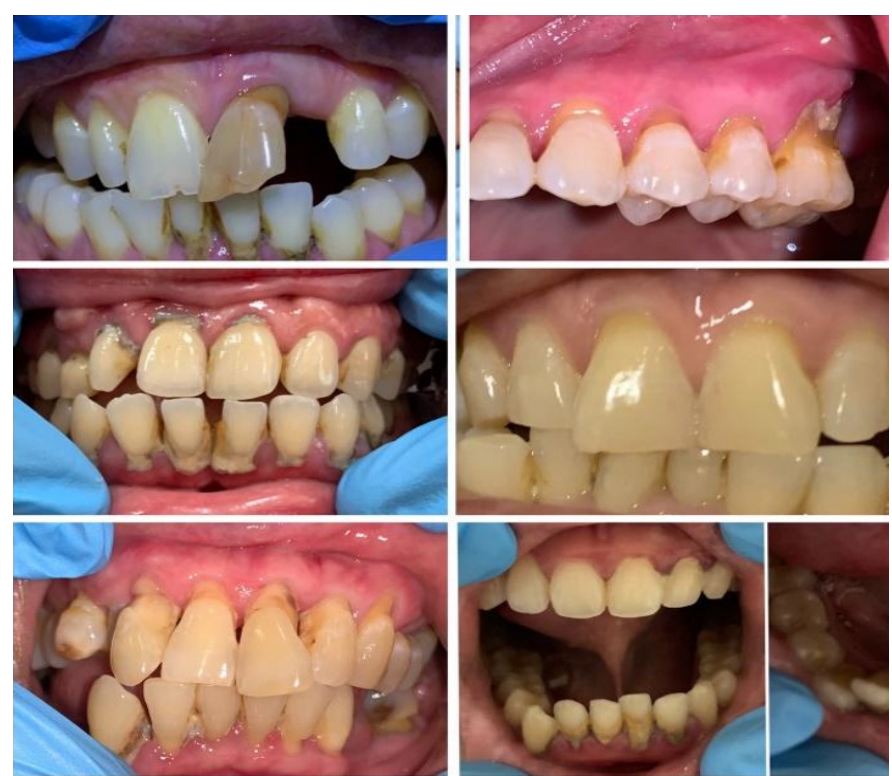

Figure 1. Periodontal condition of subjects. The figure presented are personal documentation during the research

Table 6. Periodontitis case in subjects based on the duration of using inhalation drugs

\begin{tabular}{cccc}
\hline Duration of Using Inhalation Drugs & Total Subject & Periodontitis Case & $\begin{array}{c}\text { Percentage } \\
(\%)\end{array}$ \\
\hline $1-3$ years & 24 & 17 & 70 \\
$4-5$ years & 4 & 4 & 100 \\
$\geq 6$ years & 2 & 2 & 100 \\
\hline
\end{tabular}

Table 7. Periodontitis case in subjects based on the type of inhalation drugs

\begin{tabular}{|c|c|c|c|}
\hline Inhalation drugs & Total Subject & Periodontitis Case & $\begin{array}{c}\text { Percentage } \\
(\%)\end{array}$ \\
\hline Seretide $^{\mathrm{TM}}(\mathrm{DPI})$ & 10 & 7 & 70 \\
\hline Symbicort ${ }^{T M}(D P I)$ & 4 & 2 & 50 \\
\hline $\operatorname{Berotec}^{\mathrm{TM}}(\mathrm{MDI})$ & 1 & 1 & 100 \\
\hline Seretide $^{T M}(D P I)$, salbulin ${ }^{T M}(M D I)$ & 5 & 5 & 100 \\
\hline Seretide $^{T M}(D P I)$, berotec $^{T M}(M D I)$ & 4 & 4 & 100 \\
\hline Symbicort $^{T M}(D P I)$, salbulin ${ }^{T M}(M D I)$ & 2 & 0 & 0 \\
\hline Symbicort $^{\mathrm{TM}}(\mathrm{DPI})$, berotec ${ }^{\mathrm{TM}}(\mathrm{MDI})$ & 2 & 2 & 100 \\
\hline Seretide $^{\text {TM }}$ or symbicort ${ }^{T M}(D P I)$, retaphyl ${ }^{T M}$ (tablet) & 2 & 2 & 100 \\
\hline
\end{tabular}

Table 6 presents the total periodontitis case in subjects based on the duration of using inhalation drugs. All subjects who used inhalation drugs for more than 3 years had periodontitis and 17 of 24 subjects who used drugs for 1-3 years had periodontitis.

Table 7 presents the total of periodontitis cases in subjects based on the type of inhalation drugs used.The percentage of periodontitis is higher on the subject using Seretide ${ }^{\mathrm{TM}}$ rather than Symbicort ${ }^{\mathrm{m}}$.

\section{DISCUSSION}

Periodontal disease is a disease involving destruction of the supporting tissues of the tooth initiated by the accumulation of plaque adhering to the tooth. ${ }^{13}$ Periodontal clinical features data of subjects are processed to determine the number of subjects with periodontal disease using the CDC/AAP case definition of periodontitis. Based on data grouping, 23 subjects $(76.7 \%)$ are found to have periodontitis, which is quite high. 
To be specific, one subject is found to have mild periodontitis and 22 subjects have moderate periodontitis. In relation to subjects' age, $40 \%$ of patients aged $\geq 50$ years and nearly $50 \%$ of patients aged $\geq 65$ years have mild to moderate periodontal destruction. ${ }^{14}$

Some researchers have been conducted to look at periodontal conditions associated with asthmatics. Laurikainen and Kuusisto ${ }^{18}$ and Khasawneh et al. ${ }^{19}$ researches comparing the percentage of periodontal diseases in subjects with asthma and without asthma showed patients with asthma conditions had a higher percentage of periodontal diseases. Previous research also supported the results of this study.

The periodontal condition is influenced by the treatment of asthma in the subject. It has been found previously that inhalation asthma medication has side effects on the oral cavity. ${ }^{20}$ Research by McDeera et al., Shashikciran et al., and Stensson et al. stated that asthmatics had worse periodontal health than non-asthmatics. The main factor of periodontal disease is the interaction between bacteria and host immune factors. ${ }^{14}$ Oral bacteria are opportunistic and will develop when an imbalance occurs..$^{21,22}$

The content of $B 2$ agonists in inhaled drugs will affect a decreasing level of salivary flow and concentration of Ig A secretion. ${ }^{23}$ Hence, the role of saliva as a periodontal defense mechanism through the functions of lubrication, cleansing, buffering ability, and anti-bacterial action will be decreasing as the risk of periodontal disease increasing. ${ }^{14,24} \mathrm{Also}$, the use of high doses of inhaled corticosteroids for a longer period can reduce the bone mineral density in which it will impact on the onset and progression of periodontal disease. ${ }^{25}$ Bronchial asthma is a chronic inflammatory disease characterized by symptoms of wheezing, shortness of breath, heavy feeling in the chest, and cough which can vary from time to time and in intensity along with the variation in the limited expiratory airflow. ${ }^{1}$

Based on the data of the subject characteristics in Table 1, the prevalence of asthma patients in this study is greater in women. As puberty hits, the prevalence of asthma in women is increasing compared to men. This cause by hormonal factor where female estrogen hormone has a pro-inflammatory effect that will increase the occurrence of asthma. ${ }^{26}$ Asthma patients need asthma treatment to relieve symptoms and achieve asthma controlled state. ${ }^{1}$ Asthma medication consists of bronchodilators/relievers to dilate the airways, and anti-inflammatory/ controller drugs to treat inflammation and control asthma. ${ }^{1,7}$

In this study, 29 subjects used a controller drug combination of inhaled corticosteroids (ICS) with long-acting B2 agonists (LABA) with the trademark Seretide ${ }^{T M}$ (fluticasone and salmeterol) or Symbicort ${ }^{\mathrm{TM}}$ (budesonide and formoterol fumarate dihydrate) and 1 other subject used bronchodilators from the short-acting $B 2$ agonist (SABA) in the form of Berotec $®$ (fenoterol). From 29 subjects, 13 of them used a combination of Seretide/Symbicort with additional bronchodilators in the form of Salbulin $₫ /$ Berotec $₫ /$ Retaphyl $($ tablets. Salbulin $®$ contains salbutamol sulfate and Retaphyl tablets were bronchodilators of the methylsantin group containing theophylline.

The type of medication used by patients describes asthma severity. The use of bronchodilators in the form of short-acting $B 2$ agonist (SABA) as a single drug indicates intermittent asthma while the use of the controller drug (Seretide ${ }^{\mathrm{TM}} /$ Symbicort $^{\mathrm{TM}}$ ) with or without bronchodilator indicates persistent asthma in the subject. ${ }^{9}$ The length of time of drug use or asthma treatment depends on the level of asthma control achieved by the patients so that the time of use of the drug varies in every subject. Decreased treatment can be made after achieving a state of well-controlled asthma for three to sixth months based on the assessment of the control status. ${ }^{7}$

The inclusion criteria in this study were bronchial asthma patients who used inhalation drugs for at least one year. Table 6 shows the relation between periodontal disease in the subject and the duration of inhalation drugs used. Note the number of periodontitis found is increased over the period of time usage of inhalation drugs. The longer the drug is used, the more destruction will happen in the periodontal, making the risk of periodontal disease more likely to occur.

In this research, a total of 26 patients have not achieved well-controlled asthma symptoms. Symptom control is determined based on an asthma symptom control assessment from the 
Global Initiative for Asthma (GINA) by asking 4 fundamental questions. ${ }^{1}$ One indicator of uncontrolled asthma symptoms is waking up at night due to asthma attacks. This condition can affect the development of the subjects' periodontal conditions in which salivary flow peaks during the day and decreases during sleep at night. ${ }^{27}$ The lower flow of saliva causes a greater impact when the patient breathes through the mouth or use medication and is not followed by proper gargling when the patient awakes at night.

Seretide $^{T M}$ and Symbicort ${ }^{T M}$ are the inhaled drugs the subjects are using and they belong to DPI inhalers. DPI inhalers contain lactose monohydrate. This ingredient is used to prevent aggregation and to increase the flow of the powder before aerosolization and to give a sweet taste when the device is used. ${ }^{28}$ In Seretide ${ }^{T M}$ inhaler (a combination of fluticasone propionate and salmeterol), $12.5 \mathrm{mg}$ of lactose monohydrate is found per one dose of use; on the other hand, the Symbicort ${ }^{T M}$ inhaler (a combination of budesonide and formoterol) has a lower lactose content of $0.73 \mathrm{mg}$.

The use of DPI can reduce the plaque $\mathrm{pH}$ to $<5.5$. This acidic condition is making the plaque bacteria easier to grow and increases the incidence of periodontal disease. Christof and Karova ${ }^{23}$ stated that the combination of fluticasone propionate and salmeterol in Seretide decreases salivary and plaque $\mathrm{pH}$ most substantially and for the longest time. Christof and Karova ${ }^{23}$ 's statement is in line with this study results where the percentage of periodontitis is higher on the use of Seretide ${ }^{\mathrm{TM}}$ rather than Symbicort ${ }^{\mathrm{TM}}$. The research conducted by Ayinampudi et al. ${ }^{29}$ also shows that the percentage of periodontitis is higher in the use of fluticasone inhalers in which the Seretide content is fluticasone; consequently, this result also supported by the results of Ayinampudi et al..$^{29}$

Apart from being influenced by the side effects of asthma medication, the periodontal condition experienced is also indirectly influenced by the subject's habit of consuming sweet foods and breathing through the mouth. Breathing through the mouth can lead to dehydration of the gingival surface, decrease epithelial resistance to bacterial plaque, and lack of salivary auto cleaning. ${ }^{30}$ Meanwhile, high sugar foods intake will increase plaque formation in the mouth.
Plaque is the main agent that initiates periodontal disease. The development of plaque causes an inflammatory reaction in periodontal tissue that will continue to develop when not supported by good oral hygiene. Most subjects in this study have been brushing their teeth twice a day but there is still a lot of calculus found.

Tooth brushing plays an important role in the mechanical cleaning of the plaque where the remaining plaque can be mineralized and form calculus. The calculus that is formed will provide more retention to plaque microorganisms. ${ }^{14}$ The calculus that is still widely found in the subjects of this study is possibly caused by the subject's lack of knowledge about when and how to brush their teeth well and properly, resulting in an unoptimized cleaning. In addition, many of the subjects have never visited the dentist in the past 1 year and a total of 8 subjects admit having never received treatment from a dentist in their lifetime. This illustrates the subjects' lack of awareness about their oral health, and the subjects only visited the dentist when experiencing severe complaints and not performing regular controls.

Considering how inhalation drugs can affect oral health, asthmatic patients need to pay attention to their oral cavity. Oral hygiene treatment is mandatory to reduce the side effects of accepted asthma treatment. Treatments including scaling and root planing measures to remove plaque and calculus from the tooth surface and thorough cleaning of the oral cavity. Meta-analysis research concluded that poor oral hygiene can increase the risk of periodontitis two to five times compared to good oral hygiene. ${ }^{31}$ The American Dental Association (ADA) recommends individuals to brush their teeth twice a day and use dental floss or with an interdental brush once a day to effectively remove biofilms. ${ }^{14}$

The use of toothbrushes, duration, and techniques of tooth brushing must be considered by asthmatics in maintaining periodontal health. The toothbrush used is a brush with fine bristles of nylon material with a two minutes brushing time. ${ }^{32}$ The recommended brushing technique is the sulcular brushing technique with a vibrating motion so that it can reach the gingival margin area to remove the supra gingival plaque and some sub gingival plaque. This condition can be achieved by applying the bass technique for their tooth 
brushing method. ${ }^{14}$ Asthma patients in this study have a high percentage of periodontitis. However, there are limitations in assessing periodontitis in subjects: the additional information regarding the previous history of periodontal disease is not obtained. Moreover, there has not been found a universal classification in determining periodontal conditions so that there can be differences in periodontal condition parameters that can affect the percentage of results in several related studies.

\section{CONCLUSION}

Bronchial asthma patients who used inhalation drugs for at least one year had a gingival bleeding, loss of clinical attachment, periodontal pocket. Therefore, bronchial asthma patients who used inhalation drugs had a risk of periodontitis.

\section{REFERENCES}

1. Global Initiative for Asthma. Global strategy for asthma management and prevention;2019.164 p. Available from: www.ginasthma.org

2. Gomes-Filho IS, Soledade-Marques KR, Seixas da Cruz S, de Santana Passos-Soares J, Trindade $\mathrm{SC}$, Barreto ML, et al. Does periodontal infection have an effect on severe asthma in adults? J Periodontol. 2014;85:e179-187.DOI: 10.1902/jop.2013.130509

3. Nalina $\mathrm{N}$, Chandra $M$, Umashankar. Assessment of quality of life in bronchial asthma patients. Int J Med Public Health. 2015; 5(1): 93-7.DOI: 10.4103/2230-8598.151270

4. 4. Keleș S, Aycan Yılmaz N. Asthma and Its Impacts on Oral Health. Meandros Medical Dental Journal. 2016; 17: 35-8. DOI: $10.4274 /$ meandros.2569

5. World Health Organization [Internet];2021. Asthma; (Updated 2021 May 3; cited 2021 Sep 28].available from: https://www.who.int/ news-room/fact-sheets/detail/asthma

6. Ministry of Health of the Republic of Indonesia. Primary outcome of basic health research 2018. 2018; 53(9): 45-50.

7. Ichinose $M$, Sugiura $H$, Nagase $H$, Yamaguchi $M$, Inoue $\mathrm{H}$, Sagara $\mathrm{H}$, et al. Japanese guidelines for adult asthma 2017. Allergol Int. 2017; 66(2):163-89. DOI: 10.1016/j.alit.2016.12.005
8. Moraschini V, de Albuquerque CalasansMaia J, Diuana Calasans-Maia M. Association between asthma and periodontal disease: a systematic review and meta-analysis. Journal of Periodontology. 2017;1-20.DOI: 10.1902/ jop.2017.170363

9. Nanda A, Wasan AN. Asthma in adults. Medl Clin North Am. 2019; 104(1): 95-108.DOI: 10.1016/j.mcna.2019.08.013

10. McCracken JL, Veeranki SP, Ameredes BT, Calhoun WJ. Diagnosis and management of asthma in adults a review. JAMA - J Am Med Assoc. 2017; 318(3): 279 290. DOI: $10.1001 /$ jama.2017.8372

11. Shen T-C, Chang P-Y, Lin C-L, Wei C-C, Tu $\mathrm{C}-\mathrm{Y}$, Hsia T-C, et al. Risk of periodontal disease in patients with asthma: a nationwide population-based retrospective cohort study. J Periodontol. 2017; 88(8): 723-30. DOI: 10.1902/jop.2017.160414

12. Keleș S, Yılmaz NA. Asthma and its impacts on oral health. Meandros Medical And Dental Journal. 2016; 17(1): 35-8.

13. Scannapieco FA, Cantos A. Oral inflammation and infection, and chronic medical diseases: implications for the elderly. Periodontology 2000. 2016; 72(1):153-75.

14. Newman MG, Takei HH, Klokkevold PR. Newman and Carranza's Clinical Periodontology. $13^{\text {th }}$ Ed. China: Elsevier; 2019. 19,32 , 55,89,159,195,208,237,250 426,506$520,531 \mathrm{p}$.

15. Wilmann DE, Nield-Gehrig JS. Foundation of Periodontics for Dental Hygienist. $3^{\text {rd }}$ Ed. China: Wolters Kluwer; 2011. 236 p.

16. Bhardwaj VK, Fotedar S, Sharma D, Jhingta P, Negi N, Thakur AS, et al. Association between asthma and chronic periodontitis- A CaseControl Study in Shimla-Himachal Pradesh. J Indian Assoc Public Heal Dent. 2017; 15(4): 319-22. DOI: 10.4103/jiaphd.jiaphd_85_16

17. Uppal RS, Brar R, Goel A. Association between Asthma and Chronic Periodontitis: A Clinical Study. Pakistan Oral Dent J. 2015; 35(3): 44851.

18. Laurikainen K, Kuusisto P. Comparison of the oral health status and salivary flow rate of asthmatic patients with those of nonasthmatic adults - Results of a pilot study. Allergy Eur J Allergy Clin Immunol. 1998; 53(3): 316-9. DOI: 
10.1111/j.1398-9995.1998.tb03894.x

19. Khasawneh B, Alhabashneh R, Ibrahim $F$. The association between bronchial asthma and periodontitis: A case-control study in jordan. J Asthma. 2018; 56(4): 404-10. DOI: 10.1080/02770903.2018.1466315

20. Godara N, Godara R, Khullar M. Impact of inhalation therapy on oral health. Lung India. 2011; 28(4): 272-5. DOI: 10.4103/09702113.85689

21. Manji F, Dahlen G, Fejerskov O. Caries and periodontitis: Contesting the conventional wisdom on their aetiology. Caries Res. 2018;52(6): 548-64. DOI: 10.1159/000488948

22. How KY, Song KP, Chan KG. Porphyromonas gingivalis: An overview of periodontopathic pathogen below the gum line. Front Microbiol. 2016; 7(2): 1-14. DOI: 10.3389/ fmicb.2016.00053

23. Karova E, Christoff G. Acidity of unstimulated saliva and dental plaque in asthmatics, treated with inhaled corticosteroids and long-acting sympathicomimetics. J of IMAB. 2012; 18(4): 219-23. DOI:10.5272/jimab.2012184.219

24. Mariotti A, Hefti AF. Defining periodontal health. BMC Oral Health. 2015; 15(1): 1-18. DOI: 10.1186/1472-6831-15-S1-S6

25. 25. Heffler E, Madeira LNG, Ferrando $M$, Puggioni F, Racca F, Malvezzi L, et al. Inhaled corticosteroids safety and adverse effects in patients with asthma. J Allergy Clin Immunol Pract. 2018; 6(3): 776-81. DOI: 10.1016/j. jaip.2018.01.025

26. Fuseini $\mathrm{H}$, Newcomb DC. Mechanisms driving gender differences in asthma. Physiol Behav. 2017; 17(3): 139-48. DOI: $10.1007 / \mathrm{s} 11882-$ 017-0686-1

27. Dawood IM, El-Samarrai S. Saliva and oral health. Int J Adv Res Biol Sci. 2018; 5(7): 1-5. DOI: 10.22192/ijarbs

28. Lavorini F, Pistolesi M, Usmani OS. Recent advances in capsule-based dry powder inhaler technology. Multidiscip Respir Med. 2017; 12(1): 1-7. DOI: 10.1186/s40248-017-0092-5

29. Ayinampudi B, Gannepalli A, Pacha V, Kumar J, Khaled S, Naveed M. Association between oral manifestations and inhaler use in asthmatic and chronic obstructive pulmonary disease patients. J Dr NTR Univ Heal Sci. 2016; 5(1): 17-23. DOI: $10.4103 / 2277-8632.178950$

30. Triana CBEG, Ali AH, León IBG. Mouth breathing and its relationship to some oral and medical conditions: Physiopathological mechanisms involved. Rev Habanera Ciencias Médicas. 2016; 15(2): 200-12.

31. Lertpimonchai A, Rattanasiri S, Arj-Ong Vallibhakara S, Attia J, Thakkinstian A. The association between oral hygiene and periodontitis: a systematic review and metaanalysis. Int Dent J. 2017; 67(6): 332-43. DOI: 10.1111/idj.12317

32. Darby ML, Walsh MM. Dental Hygiene Theory and Practice. $4^{\text {th }}$ Ed. China: Elsevier Saunders; 2015. 397 p. 